\title{
Yoğun Sulama Uygulamalarının Taban Suyu Kalitesi ve Derinlikleri Üzerine Olan Zamansal ve Mekansal Etkilerinin Değerlendirilmesi: Akarsu Sulama Birliği Sahası Örneği
}

Evaluation of Spati-Temporal Effects of Intense Irrigation Practices on Groundwater Quality and Depths: A Case Study in the Akarsu Irrigation District Area

\section{Mahmut ÇETIN ${ }^{1}$, Harun KAMAN ${ }^{2, *}$, Sertan SESVEREN ${ }^{3}$}

\section{$\ddot{\mathbf{O} z}$}

Yoğun sulama uygulamalarının yapıldığı tarımsal havzalarda kimi sorunlar meydana gelebilmektedir. Sulama şebekesindeki ve sulama yönetimindeki eksiklikler, düşük sulama randımanı, ağır toprak bünyesi ve tarla içi drenaj sistemlerinin yetersizliği vb. nedenler topraklarda tuzlanma, drenaj ve taban suyu tuzluluğu sorunlarına neden olmaktadır. Anılan sorunlar, bitkisel üretimi olumsuz yönde etkilemektedir. Bu nedenle, zaman ve mekân boyutundaki taban suyu gözlemleri, sürdürülebilir su kaynakları yönetimi için son derece önemli bilgilerin elde edilmesini sağlamaktadır. Bu çalışmada, geniş bir sulama havzasında taban suyu seviyesi ve taban suyu kalitesinin zaman ve mekân boyutunda değerlendirilmesi amaçlanmıştır. Araştırma, Türkiye'nin güneyinde Aşağı Seyhan Ovası'nda (ASO) yer alan, Akarsu Sulama Birliği (ASB) sahasında yürütülmüsştür. Araştırma alanı, 60 yıldan bu yana sulanmaktadır. Sulama şebekesi, üreticilerin gece ve gündüz sulama uygulamalarını sürekli yapabilmeleri için “devamlı akış yöntemi”ne göre işletilmektedir. Taban suyu derinliği ve taban suyu kalite gözlemleri 108 adet drenaj gözlem kuyusunda yapılmıştır. Gözlemler, yılda dört farklı dönemde (şubat, nisan, temmuz ve ekim aylarında) gerçekleşmiştir. Kış yağışlarının, araştırma alanın üçte birinden fazlasında, aşırı drenaj sorununa neden olduğu ortaya konulmuştur. Akarsu Sulama Birliği sahasının kuzey kesimlerinde, taban suyu derinliğinin kritik seviyelerde $(<1 \mathrm{~m})$ olduğu tespit edilmiştir. Taban suyu tuzluluğu alansal ortalamaları, kritik değer olan $5 \mathrm{dS} \mathrm{m}^{-1}$ ile karşılaştırıldığında oldukça düşük bulunmuştur. Bununla birlikte, ortalama taban suyu tuzluluğu kış aylarında yağışların seyreltme etkisi nedeniyle en düşük değere ulaşmıştır. Alanın \%15-26'sında, kış ayı hariç yıl boyunca her zaman taban suyu tuzluluğu $>5 \mathrm{dS} \mathrm{m}^{-1}$ değerlerini almıştır. Taban suyundaki toplam çc̈zünmüş tuzlar (TDS), sulama mevsiminin sonunda en yüksek seviyeye ulaşmıştır. Alansal ortalama taban suyu alkaliliği (Sodyum Adsorpsiyon Oranı-SAR), eşik SAR değerinin altında $(\mathrm{SAR}<13)$ bulunmuştur. Araştırma alanındaki yetiştiricilerin yoğun şekilde sulamalarını gündüz yapmalarından dolayı fazla sulama suyu gece boyunca drenaj kanallarına tahliye olmaktadır. Şebeke alanındaki sulama yönetiminden sorumlu yetkililerin, gece sulama uygulamalarını teşvik etmeleri; hakim yüzey sulama yöntemleri yerine, sulama suyundan tasarruf sağlayan yağmurlama ve düşük basınçlı damla sulama yöntemlerini yaygınlaştırmaya yönelik faaliyetlere ağırlık vermeleri önerilmiştir.

Anahtar Kelimeler: Sulama randımanı, Toplam çözünmüş tuz, Taban suyu alkaliliği, Sulama yönetimi

\footnotetext{
2*Sorumlu Yazar/Corresponding Author: Harun Kaman, Akdeniz Üniversitesi, Ziraat Fakültesi, Tarımsal Yapılar ve Sulama Bölümü, 07058 Kampüs, Antalya, Türkiye. E-mail: hkaraman@akdeniz.edu.tr (iD) OrcID: 0000-0001-9308-3690

${ }^{1}$ Mahmut Çetin, Çukurova Üniversitesi, Ziraat Fakültesi, Tarımsal Yapılar ve Sulama Bölümü, 01330 Balcalı, Adana, Türkiye. E-mail: mcet64@cu.edu.tr

(D) OrcID: 0000-0001-5751-0958

${ }^{3}$ Sertan Sesveren, Kahramanmaraş Sütçü İmam Üniversitesi, Ziraat Fakültesi, Biyosistem Mühendisliği Bölümü, Avşar Yerleşkesi 46100 Kahramanmaraş, Türkiye. E-mail: sesveren@ksu.edu.tr ${ }^{(D)}$ OrcID: 0000-0002-5163-7066

Atıf/Citation: Çetin, M., Kaman, H., Sesveren, S. Yoğun Sulama Uygulamalarının Taban Suyu Derinlikleri Üzerine Olan Zamansal ve Mekansal Etkilerinin Değerlendirilmesi: Akarsu Sulama Birliği Sahası Örneği. Tekirdă̆ Ziraat Fakültesi Dergisi, 18 (4), 649-659.

(CBu çalışma Tekirdağ Namık Kemal Üniversitesi tarafından Creative Commons Lisansı (https://creativecommons.org/licenses/by-nc/4.0/) kapsamında yayınlanmıştır. Tekirdağ 2021 


\begin{abstract}
Some site specific problems may arise in agricultural catchments where irrigation practices are intensive. Some causes such as shortcomings in irrigation water management, low irrigation efficiencies, heavy soil texture, insufficiencies in field drainage systems, etc. mostly result in problems of salinity in soil profile, waterlogging and groundwater salinity. Those problems negatively affect crop yield. In turn, drainage observations in space and time provide important information for sustainable water resources management. In this study, it is aimed at evaluating spatio-temporal characteristics in quality and quantity of groundwater in a large irrigation district area. In line with the objective, the study was conducted in the Akarsu Irrigation District (AID) area of the Lower Seyhan Plain (LSP), located in the south of Turkey. Irrigation has been practiced in the study area for more than 60-year. Irrigation scheme has been managed by adopting continuous flow regime so as to ensure continuous water supply for the growers at night and during the day. In this research, groundwater depth and groundwater quality data were collected from 108 drainage observation wells. Observations in each well were made four times a year, i.e. in February, April, July and October. It was figured out that severe drainage problems occurred in more than onethird of study area due to heavy winter rains. It was determined that depth of the groundwater was less than the critical levels $(<1 \mathrm{~m})$ in the northern parts of Akarsu command area. On the other hand, areal averages of groundwater salinity were found to be quite low compared to the critical value of $5 \mathrm{dS} \mathrm{m}^{-1}$. However, the average groundwater salinity reached at its lowest value in cool season, due to the dilution effect of rainfall in winter. Groundwater salinity was determined to be $>5 \mathrm{dS} \mathrm{m}^{-1}$ in the 15 to $26 \%$ of the area throughout the year, except winter season. Total dissolved solid (TDS) in the groundwater body were found to be the highest at the end of the irrigation season, i.e. in October. Areal average of excess sodium, i.e Sodium Adsorption Ratio (SAR), in groundwater system was found to be less than the threshold SAR value of 13. Excessive irrigation water is discharged into the drainage channels during the night because the growers in the study area irrigate intensely during the day. Authorities in charge of irrigation management in the area are supposed to encourage irrigators to get used to nocturnal irrigation practices. Additionally, it was recommended that more effort be made in order to extend areas where sprinkler or low pressure drip irrigation systems are practiced instead of surface irrigation methods.
\end{abstract}

Keywords: Irrigation efficiency, Total dissolved solid, Groundwater alkalinity, Irrigation management 


\section{Giriş}

Tarımsal üretimde sulama, verim artışı sağlayan önemli bir uygulamadır. Ancak, sulamanın yanlış uygulanması tuzluluk vb sorunları meydana getirmektedir. Genel olarak, sulanan tarım alanlarında yüksek ve tuzlu taban suyu problemi meydana gelebilmektedir ((İstanbulluoğlu ve ark., 2006; Konukcu ve Akbuğa, 2006). Bununla birlikte, iklim değişikliği günümüzde önemli bir olgudur. Küresel ısınma ve buna bağlı olarak ortaya çıkan kuraklık, suya olan talebi arttırmaktadır. Bu bağlamda, toprak ve su kaynaklarının iyi yönetilmesi ve geliştirilmesinin önemi apaçık ortadadır. Toprak ve su kaynaklarının iyi yönetimi ve geliştirilmesiyle kaynaklar rasyonel kullanılabilmekte, tarımsal üretimde büyük artışlar sağlanabilmektedir. Ancak, Çetin ve Özcan (1999) tarafından da vurgulandığı üzere, sulama ve drenaj yatırımlarının pahalı olması, planlamalarda meydana gelebilecek muhtemel hatalar vb. faktörler yatırımların maliyetini yükseltmektedir. Bu nedenle, sulama ve drenaj yatırımlarında su-bitki-toprak-atmosfer ilişkilerinin çok iyi araştırılması ve bilinmesi gerekmektedir.

Genel olarak her toprak çeşidinin kendine özgü bir kullanım ve yönetim isteği vardır (Çetin ve Özcan, 1999). $\mathrm{Bu}$ nedenle, toprakların özellikle sulama koşulları altında iyileştirilme olanakları dikkate alınmalıdır. Aksi durumda, dünyada olduğu gibi ülkemizin birçok yöresinde de drenaj, tuzluluk ve alkalilik sorunlarının meydana gelmesi kaçınılmazdır. Buna ilave olarak topoğrafik yapı, doğal drenaj durumu, iklim özellikleri, jeolojik durum, ana materyal yapısı ve denize olan mesafe gibi doğal etkenler de tuzluluğa yol açmaktadır (Amezketa, 2006). Tuzluluk, sulu tarımın sürekliliğini engelleyen ve bitkisel verimi sınırlayan en önemli sorunlardan birisidir. Eğer tuzluluk kontrol altına alınamazsa sulanabilir alanların tarım dışı kalması beklenmelidir. Dünyada, 100'den fazla ülke tuzluluktan etkilenmektedir (Szabolcs, 1989). Her yıl yaklaşık $4 \times 10^{4}$ ha alan tuzluluk sorunu nedeniyle tarım dışı kalmakta (Lamsal ve ark., 1999), bu rakamlar tedrici olarak gün geçtikçe artış göstermektedir. Ülkemizde de tuzluluk problemi bulunan araziler, sulanabilir arazinin \%20'sine ulaşmışır (Konak ve ark., 1999); önlem alınmadığı takdirde bu alanların artması beklenmektedir.

Su kaynaklarından en yüksek düzeyde faydanın sağlanması, suyun var olması ile yeterli olmayıp, su kalitesinin de amacına uygun olması gerekmektedir (FAO, 2001; Cetin ve Kirda, 2003). Ülkemizde, tarım en çok su talep eden sektör konumundadır (Çetin ve Özcan, 1999; Gündoğdu, 2004; Çetin ve ark., 2007). Son y1llarda hızlı nüfus artışı ve sanayileşme suya olan talebi giderek arttırmakta ve bunun bir sonucu olarak da su kitlığı sorunu tetiklenmektedir. Büyükcangaz ve Değirmenci (2002) tarafından da belirtildiği gibi, günümüzde iklim değişikliği ve olası sonuçları yaygın olarak tarış̧ılmaktadır. Bu tartışmalar, su kaynaklarının geliştirilmesi, korunması ve etkin bir şekilde yönetiminde uygun stratejilerin hızlı bir şekilde belirlenmesini ve uygulamaya konulmasının gerekliliğini ortaya koymaktadır. Ülkemiz sulu tarım alanlarında sulama randımanlarının istenilen düzeylere yükseltilememesi önemli bir sorundur (Cetin, 2020). Bu nedenle, tarım sektöründe suyun daha etkin kullanılması sonucunda önemli oranda su tasarrufu (FAO, 2001; FAO, 2002) sağlanabileceği öngörülmektedir. Bu nedenle, deniz ve okyanuslara yakın olan kıyı ovalarında (Said ve ark., 2021) su kalitesinin izlenmesi özel önem arz etmektedir. Düz ve taban arazilerde de sürdürülebilir tarımsal üretim ve su yönetimi için taban suyu seviyesi ve taban suyu kalitesinin periyodik olarak izlenmesi ve irdelenmesi gerekmektedir. Taban suyu seviyesi ve taban suyu kalitesi durumunun takip edilmesi sonucu sağlanacak bilgiler vasıtasıyla muhtemel sorunlar karşısında tedbirler alınabilecektir. Taban suyu kalitesinin düşük ve taban suyu sorunu olan yerlerde, gelecekte toprakların geçirgenliğinin azalacağı, tuzluluk ve alkalilik gibi sorunların yaygınlaşma riskinin artabileceğine vurgu yapılmaktadır (FAO, 2001; Cetin ve Kirda, 2003; Demir ve Antepli, 2004).

İyi kalitede sulama suyu kullanılmış olsa bile, sulama uygulamalarının çok yoğun olarak yapıldığı tarım alanlarında; sulama yönetimindeki eksiklikler, düşük sulama randımanı, ağır toprak bünyesi ve tarla içi drenaj sistemlerinin yetersizliği vb. nedenlerle drenaj ve taban suyu tuzluluğu sorunları ortaya çıkmaktadır. Anılan sorunlar, bitkisel üretimi olumsuz yönde etkilemektedir. Bu nedenle, taban suyu kalitesi ve kantitesine ilişkin gözlemler sürdürülebilir su kaynakları yönetimi için son derece önemli bilgilerin elde edilmesini sağlamaktadır. Bu çalışmada, büyük ölçekli bir sulama şebeke alanında taban suyu derinliği ve kalitesinin zaman ve mekan boyutundaki değişimlerinin izlenmesi ve değerlendirilmesi amaçlanmıştır. 


\section{Materyal ve Metot}

Bu araştırma, Türkiye'nin güneyinde Aşağı Seyhan Ovası'nda (ASO) yer alan, 60 yıldan daha uzun bir süredir sulama ve drenaj sistemi bulunan 9495 ha genişliğindeki Akarsu Sulama Birliği (ASB) alt havzasında yürütülmüştür. Araştırma alanını içine alan ASO, 213200 ha'lık bir delta ovasını kapsar; 174088 ha alan sulu tarım arazi sinıflandırma standartlarına göre sulu tarıma uygundur (Çetin ve Özcan, 1999; Cetin ve Kirda, 2003; Çetin ve ark., 2007). ASB, $36^{\circ} 57^{\prime} 32^{\prime \prime}-36^{\circ} 50^{\prime} 43^{\prime \prime}$ kuzey enlemleri ile $35^{\circ} 40^{\prime} 22^{\prime \prime}-35^{\circ} 28^{\prime} 42^{\prime \prime}$ doğu boylamları arasında olup, Ceyhan Nehri'nin sol sahilindedir (Şekil 1). Sulama şebekesi DSİ tarafindan inşa edilip işletilmiştir. Ancak, 1994 yılında sulama şebekesi Devlet Su İşleri tarafından bir protokol ile ASB'ne devredilmiştir.

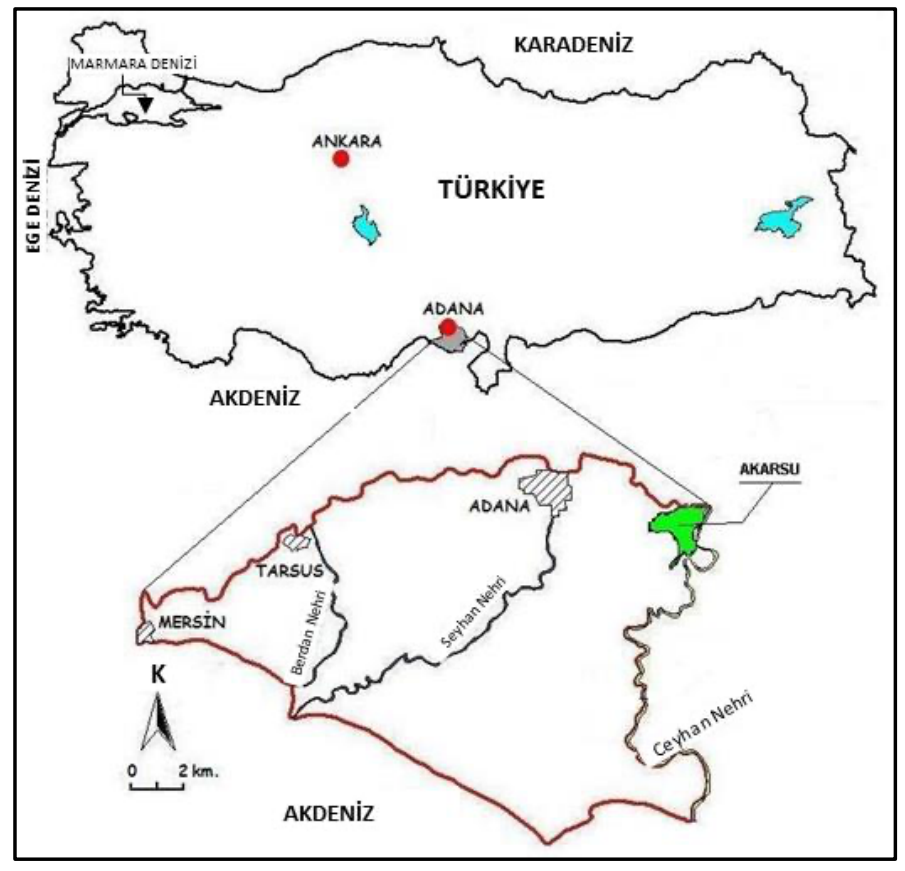

Figure 1. Location of the study area in Turkey (Kaman et al., 2011)

Şekil 1. Araştırma alanının Türkiye'deki konumu (Kaman ve ark., 2011)

Araştırma alanındaki toprakların toprak serilerine göre dağılımı incelendiğinde, en yaygın toprak serileri Arikli (30\%), Incirlik (27\%) ve Yenice (14\%) serileridir (Dinç ve ark., 1995). Diğerleri ise Ismailiye (0.9\%), Golyaka (0.5\%) ve Innapli $(0.4 \%)$ serileridir.

Araştırma alanına sulama suyu Seyhan barajından saptırılmakta olup, Seryhan Nehri'nin yıllık ortalama su verimi $6.3 \mathrm{~km}^{3} \mathrm{yll}^{-1}$ dolayındadır. Ovanın yegane su kaynağı Seyhan Nehridir; Seyhan baraj gölündeki su, sulama için iyi kalitededir $\left(E C<0.5 \mathrm{dS} \mathrm{m}^{-1}\right)$. ASO'da, genel olarak sulama randımanı düşük olan yüzey sulama yöntemleri (\%52) uygulanmakta; yağmurlama sulama ile sulanan alanlar $\% 7$, damla sulama altındaki alanlar ise $\% 41$ dolayındadır.

Akdeniz ikliminin hüküm sürdüğ̈̈ araştırma alanında yazlar sıcak ve kurak, kışlar ılık ve yağışlıdır. Yağışlar genellikle en düşük buharlaşmanın olduğu kış aylarında yağmur şeklinde düşmektedir (Çölaşan, 1970). Adana meteoroloji istasyonu gözlem sonuçlarına göre, araştırma alanı ve çevresinde ortalama sıcaklık $18.7^{\circ} \mathrm{C}$, minimum sıcaklık $13.1^{\circ} \mathrm{C}$ ve maksimum sıcaklık ise $25.2^{\circ} \mathrm{C}$ 'dir. En yüksek sıcaklıklar haziran, temmuz, ağustos ve eylül aylarında gözlemlenirken, en düşük sıcaklıklar ise aralık, ocak, şubat ve mart aylarında meydana gelmektedir (Çölaşan, 1970).

Araştırma alanındaki taban suyu gözlem noktalarının yerleri, arazide yapılan ön çalışmalar ve harita üzerinde yapılan değerlendirmelere göre belirlenmiştir. Çalışma alanına tesis edilen ilave drenaj gözlem kuyuları ile birlikte toplam 108 adet drenaj (taban suyu, TS) gözlem kuyusu izlemeye alınmıştır (Şekil 2). Drenaj gözlem kuyu koordinatları, Magellan Explorist 600 Reference Manual (Thales, 2005)'de verilen yöntem kullanılarak GPS ile (Datum=ED50) UTM olarak yerinde belirlenmiştir. 


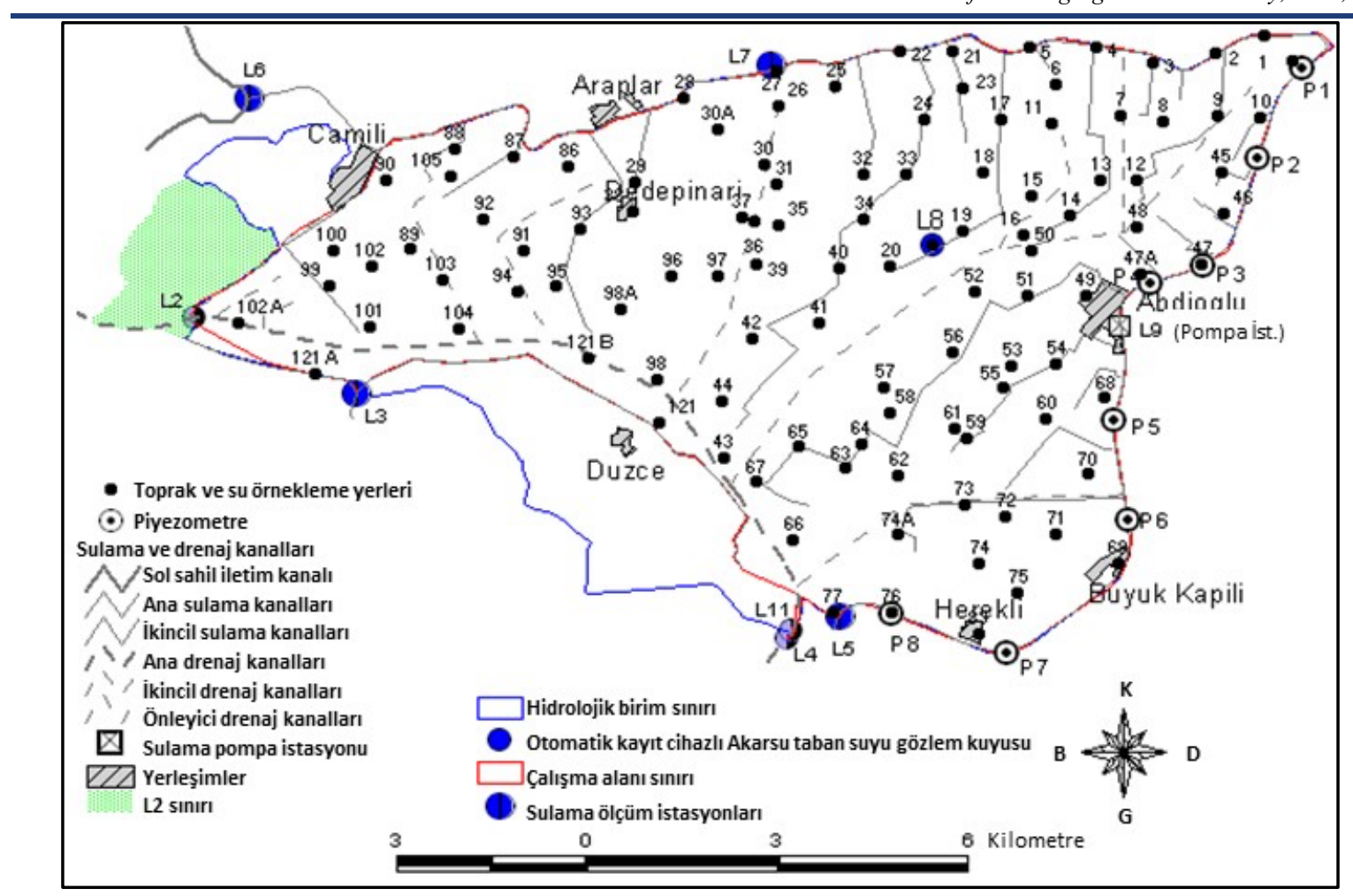

Figure 2. Spatial distribution of groundwater observation wells in research area (Kaman et al., 2011)

Şekil 2. Araştırma alanındaki drenaj gözlem kuyularının dağılımı (Kaman ve ark., 2011)

Araştırmada, 2008 yılı şubat, nisan, temmuz ve ekim aylarında yapılan taban suyu kalitesi ve derinliği gözlemleri kullanılmıştır. Taban suyu derinlikleri (m) ve taban suyu kalite parametreleri DSİ (1982), Cetin ve Diker (2003)'de belirtilen yöntemlere göre elde edilmiştir. Taban suyu kalite parametreleri olarak; elektriksel iletkenlik (EC, $\left.\mathrm{dS} \mathrm{m}^{-1}\right)$, toplam çözünmüş tuzlar (TDS, $\mathrm{g} \mathrm{L}^{-1}$ ) ile SAR değerleri incelenmiştir. Bu parametrelerin kapladığı alanlar coğrafi bilgi sistemleri (CBS) ortamında belirlenmiş ve alan yüzdeleri elde edilerek çizelgeler halinde sunulmuştur.

CBS ortamında taban suyu derinlik ve tuzluluk haritalarının çiziminde, "ters uzaklık enterpolasyon (IDWI)" tekniği (Cetin ve Diker, 2003) kullanılmıştır. Bu amaçla, çalışma alanı 0.25 ha büyüklüguünde kare hücreler oluşturacak şekilde gridlenmiştir. Her bir değiş̧enin grid hücresindeki alacağı değer, IDWI yöntemi ile kestirilmiş̧tir. IDWI yönteminin ayrıntıları ve kullanılan parametreler için Çetin ve ark. (2007)'den yararlanılmıştır.

\section{Araştırma Sonuçları ve Tartışma}

Uydu görüntüleri ve yer gözlemleri kullanılarak araştırma alanındaki bitki deseni belirlenmiştir. Araştırma havzasındaki hakim bitkiler ve dağılımı Şekil 3'te sunulmuştur. Görüleceği üzere, en fazla ekim alanına sahip olan bitki mısır olup, \%39.6 oranında alan kaplamaktadır. Narenciye bahçelerinin kapladığı alan ise \%29.2 ile birinci ürün mısır bitkisini takip etmiştir. Buğday ekilen alanların oranı \%17.7 olmuştur. Bu durumda, ikinci ürün ekim alanlarının \%18 ve daha düşük olacağı sonucuna varılmıştır. Şekil 3'te verilen ikinci ürün ekim alanları bu tespite paralel bulunmuştur. 
Cetin \& Kaman \& Sesveren

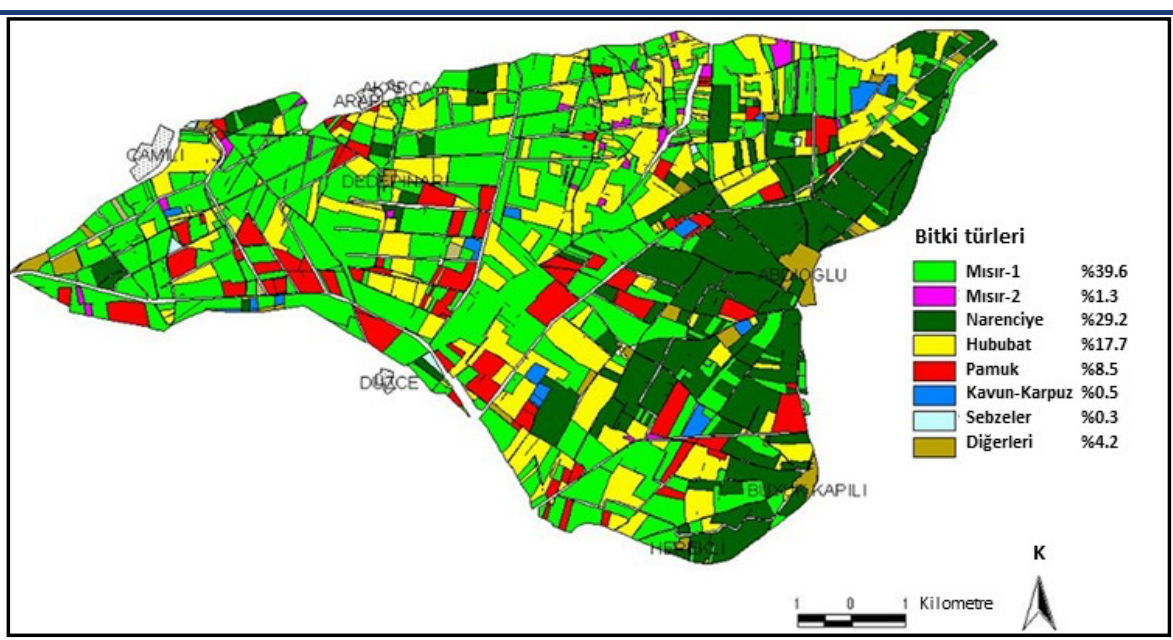

Figure 3. Spatial distribution of major crops grown in the research area

\section{Şekil 3. Araştırma alanında yetiştirilen başlıca bitkilerin dağı̆lımı}

\subsection{Taban suyu derinliğinin zamansal ve mekansal değişimi}

Tüm örnekleme dönemleri için taban suyu derinlikleri CBS ortamında işlenmiş ve araştırma havzası özelinde ortaya çıkan drenaj problem alanları haritalar üzerinde saptanmıştır. Üretilen haritaların zonal istatistikleri değerlendirilmiş, kategorize edilmek sureti ile sonuçlar çizelgelerde özetlenmiştir. Taban suyu derinliği üzerine sulama ve yağışların etkisi vardır. Bu nedenle, öncelikle araştırma alanındaki yağışların zamansal değişimleri Şekil 4'de verilmiştir. Bu şekil üzerine, araştırma alanının merkezinde yer alan bir drenaj gözlem kuyusunda gözlenen taban suyu seviyesi değişimleri de konulmak sureti ile taban suyunun yağış olaylarına olan tepkisi ortaya konulmaya çalışılmıştır. Bu grafikten, taban suyunun kış yağışlarının etkisinde olduğu açıkça görülmektedir. Bu bağlamda, Aralık/2007 ve Şubat/208 aylarında meydana gelen yüksek yağış miktarlarının sahadaki taban suyu derinliği üzerine, dolaysıyla da taban suyu seviyesine direk etki ettiği açıkça görülmektedir.

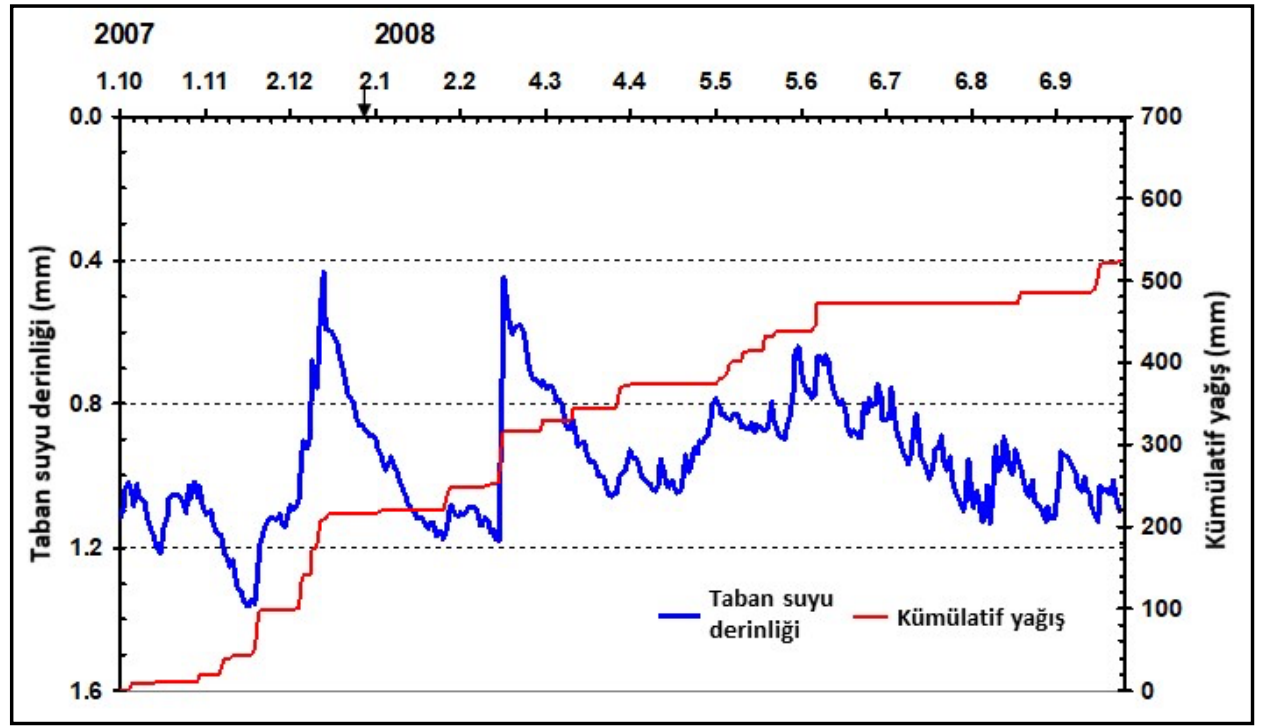

Figure 4. Temporal distribution of rainfall and groundwater elevations in in the resarch catchment

Şekil 4. Araştırma havzasındaki yağışların ve taban suyu seviyelerinin zamansal değisşimi

Araştırmanın yürütüldüğü tarım havzasında, sulama uygulamaları temmuz ayında pik değere ulaşmaktadır. Sulamanın en yoğun olduğu temmuz ayı taban suyu derinliği haritası Şekil 5'te verilmiştir. Narenciye plantasyonlarının yoğun olduğu alanlarda taban suyu derinliğinin 1.0-1.5 m arasında olduğu tespit edilmiştir. 
Araştırma alanının kuzeyinde, özellikle L7 akım gözlem istasyonu ve Araplar köyü boyunca uzanan kesimlerde, taban suyu derinliği drenaj problemi bakımından kritik seviyelere $(<1.0 \mathrm{~m})$ ulaştığı görülmüştür (Şekil 5).

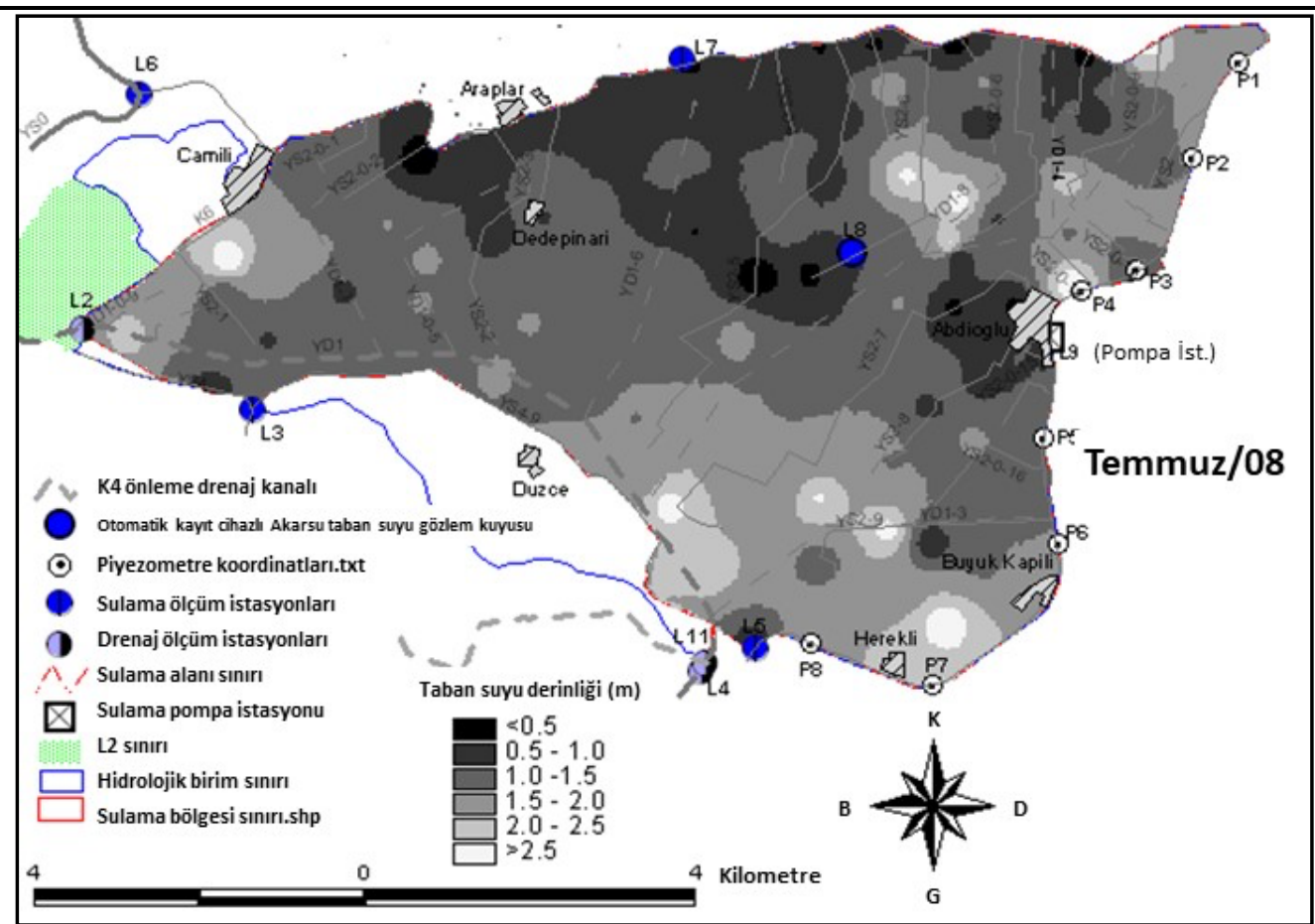

Figure 5. Spatial distribution of groundwater $(G W)$ depths in the research catchment during the peak irrigation season, i.e. July

\section{Şekil 5. Araştırma alanında sulamanın en yoğun olduğu temmuz ayında suyu derinliğinin dă̆ılımı}

Tablo 1'de ise taban suyu derinlikleri (m) ile kapladıkları alanlara (\%) ilişkin bulgular verilmiştir. En yoğun sulama mevsimi olan temmuz ayında, araştırma sahasının \%66.3'ünde taban suyu derinliğinin 1.5 m'den az olduğu; bir başka ifade ile taban suyunun bir çok bitkinin etkili kök derinliği içinde olduğu saptanmıştır (Tablo 1). Kış mevsiminde ise, şiddetli yağışların kök bölgesine süzülerek taban suyunu yükseltmesi sonucunda araştırma alanının üçte birinden fazlasında, ciddi drenaj sorunları meydana gelmiştir. Kışın şubat ayında, alansal ortalama taban suyu derinliği 1.13 m olarak hesaplanmıştır (Tablo 1). Sulama mevsiminin sonunda ciddi drenaj sorunu $(<$ $1 \mathrm{~m})$ olan alanların yüzdesi oldukça düşük (\%2.7) bulunmuştur. Yağış ve sulama sularından kaynaklanan drenaj sorunları kışın şubat ayında; yazın ise temmuz ayında meydana gelmiştir. Bu nedenle, drenaj sorununun çözümünde kış yağışları ve sulama uygulamaları dikkate alınması gereken iki faktördür.

Tablo 1. Araştırma sahasında taban suyu derinliğinin (m) alansal dă̆ılımı (\%)

Table 1. Areal coverage (\%) of groundwater depths (in the unit of $m$ ) in the research area

\begin{tabular}{cccccc}
\hline & & \multicolumn{4}{c}{ Taban suyu derinliği (m) } \\
\cline { 3 - 6 } Zaman & $\begin{array}{c}\text { Alansal ortalamalar ve } \\
\text { standart sapmaları }\end{array}$ & \multicolumn{1}{c}{$\mathbf{1 . 0}$} & $\mathbf{1 . 0 - 1 . 5}$ & $\mathbf{1 . 5 - 2 . 0}$ & $\mathbf{2 . 0 <}$ \\
\cline { 3 - 6 } & & & \multicolumn{3}{c}{ Kapladığı alan (\%) } \\
\hline Şubat/08 & $1.13 \pm 0.33$ & 35.9 & 51.4 & 11.1 & 1.7 \\
Nisan/08 & $1.38 \pm 0.28$ & 6.5 & 59.3 & 32.1 & 2.1 \\
Temmuz/08 & $1.37 \pm 0.43$ & 20.6 & 45.7 & 25.6 & 8.2 \\
Ekim/08 & $1.70 \pm 0.36$ & 2.7 & 25.8 & 51.8 & 19.6 \\
\hline
\end{tabular}

Bu araştırmanın yürütüldüğü Çukurova yöresinde Demir ve Antepli (2004) tarafından yapılan bir çalışmada, sulama uygulamalarının en yüksek düzeylere temmuz ayında ulaştığı bildirilmektedir. Bu sonuçlar, temmuz 
Cetin \& Kaman \& Sesveren

ayındaki tarımsal amaçlı su kullanımındaki artışın, drenaj sorununun şiddet ve yayılımı üzerine etki ettiği anlamına gelmektedir. Tarımsal bir havzada yapılan bu araştırmada elde edilen bulgular; Demir ve Antepli (2004), Çetin ve ark. (2007)'in aynı bölgede yaptıkları çalışma sonuçlarıyla da uyumlu bulunmuştur.

\subsection{Taban suyu tuzluluğunun zamansal değişimi}

Taban suyu kalite parametreleri olarak; taban suyu elektriksel iletkenliği (EC, $\left.\mathrm{dS} \mathrm{m}^{-1}\right)$, taban suyunda toplam çözünmüş tuzlar (TDS, $\mathrm{g} \mathrm{l}^{-1}$ ) ile taban suyunda SAR değerleri incelenmiştir. Bu parametrelerin CBS ortamında haritaları çizilerek alansal dağılımları incelenmiş, alansal dağılım yüzdeleri hesaplanarak çizelgeler halinde sunulmuştur.

Tablo 2'de araştırma sahasında yer alan drenaj gözlem kuyularından alınan su örneklerinde ölçülen taban suyu EC $\left(\mathrm{dS} \mathrm{m}^{-1}\right)$ değerleri ile alansal dağılımları (\%) sunulmuştur. Taban suyu tuzluluğunun alansal ortalamaları, kritik değer olan $5 \mathrm{dS} \mathrm{m}^{-1}$ değeri ile karşılaştırıldığında oldukça düşük olduğu dikkati çekmektedir. Bununla birlikte, ortalama taban suyu tuzluluğu, yağışların seyreltme etkisi nedeniyle kış aylarında en düşük değere ulaşmıştır. Ancak, kış aylarında taban suyu tuzluluğunun değişkenliği artmaktadır. Araştırma alanının \%10’undan fazlasında, kış ayları hariç olmak üzere, yıl boyunca taban suyu tuzluluğu $>5 \mathrm{dS} \mathrm{m}^{-1}$ olmuştur. Sulama mevsimi sonunda taban suyu tuzluluğu artmakta ve drenaj mühendisliği açısından kritik değer (Cetin ve Diker, 2003) olan $5 \mathrm{dS} \mathrm{m}^{-1}$ üzerine çıkmaktadır. Ekim ayında taban suyu tuzluluğunun $>5 \mathrm{dS} \mathrm{m}^{-1}$ olduğu alanlar, toplam alanın dörtte birinden daha büyüktür. Bu değerler, sahada yapılan literatür ile (Cetin ve Diker, 2003) uyumlu bulunmuştur.

Tablo 2. Çalışma alanında taban suyu EC (dS $\left.m^{-1}\right)$ değgerleri ile alansal dă̆ılımı (\%)

Table 2. Areal coverages (\%) of groundwater EC (dS $\left.\mathrm{m}^{-1}\right)$ values in the study area

\begin{tabular}{|c|c|c|c|c|c|c|c|}
\hline \multirow{3}{*}{ Zaman } & \multicolumn{7}{|c|}{ Taban suyu tuzluluğu (EC, dS me } \\
\hline & \multirow{2}{*}{$\begin{array}{l}\text { Alansal ortalamalar ve } \\
\text { standart sapmaları }\end{array}$} & $<2$ & $2-3$ & $3-5$ & $5-10$ & $10-30$ & $30<$ \\
\hline & & \multicolumn{6}{|c|}{ Kapladığı alan (\%) } \\
\hline Şubat/08 & $2.51 \pm 2.60$ & 59.8 & 22.7 & 10.0 & 4.1 & 3.4 & 0.0 \\
\hline Nisan/08 & $3.39 \pm 3.32$ & 39.7 & 20.8 & 23.6 & 11.4 & 4.4 & 0.1 \\
\hline Temmuz/08 & $3.00 \pm 3.30$ & 50.6 & 20.5 & 16.9 & 7.6 & 4.2 & 0.2 \\
\hline Ekim/08 & $3.80 \pm 3.55$ & 39.9 & 16.2 & 18.3 & 20.5 & 4.9 & 0.1 \\
\hline
\end{tabular}

\subsection{Taban suyunda toplam çözünmüş tuzların zamansal değişimi}

Araştırma alanındaki taban sularında gözlenen toplam çözünmüş tuzların (TDS, $\mathrm{g} \mathrm{L}^{-1}$ ) zamansal değişimleri ve kapladığı alanlar Tablo 3'te verilmiştir. Tablo incelendiğinde, taban suyundaki toplam çözünmüş tuzların alansal ortalamalarının zamana göre önemli bir değişim göstermediği ve birbirine yakın değerler aldığı görülmektedir. Sulama mevsiminin tamamlanmasından sonra, taban suyunda toplam çözünmüş tuzların ortalama değerinde hafif bir artış meydana gelmiştir. Taban suyunda toplam çözünmüş tuzların $2 \mathrm{~g} \mathrm{~L}^{-1}$ ' den büyük olduğu alanlar, yıl boyunca toplam alanın \%28'in üzerinde bulunmuştur. Sonuç olarak, taban suyunda toplam çözünmüş tuzların şiddeti ve kapladığı alanlar sulama mevsiminin sonuna doğru artmıştır.

Ülkemizde taban suyu tuzluluğunun sulama sezonunun en yoğun olduğu temmuz ayında genellikle düşük düzeylerde olduğu bilinir. Bu çalışmada da, sulamanın en yoğun olduğu dönemde aşırı sulama suyu kullanımının bir sonucu olarak temmuz ayında taban suyu örneklerinde ölçülen tuzluluk değerleri ekim ayı değerlerine kıyasla daha küçük çıkmıştır. Bununla birlikte, Cemek ve ark. (2006) sulanan alanların yaklaşık üçte birinin tuzluluktan küresel olarak etkilendiğini belirtmiştir. Benzer şekilde, Akdeniz havzasında birçok kurak ve yarı kurak bölgedeki tuzluluk, sulu tarımı tehdit etmektedir (Aragues ve ark., 2011). Drenaj mühendisliği bakımından kritik değer olarak kabul edilebilecek taban suyu tuzluluğunun 5 dS m${ }^{-1}$ 'den daha büyük (DSİ, 1982; Çetin ve Özcan, 1999; Cetin ve Kirda, 2003; Cetin ve Diker, 2003) olduğu alanların yayılımı nisan ayında \%15.8, temmuz ayında \%12 ve ekim ayında \%25.5 olarak gerçekleşmiştir (Tablo 2). ASO’da gözlenen bu değişimler Cetin ve Kirda (2003) tarafindan 
JOTAF/ Journal of Tekirdag Agricultural Faculty, 2021, 18(4)

yapılan araştırmadaki bulgulara paralel olup, Said ve ark. (2021)'de denize yakın olan kıyı akiferlerde bu hususun önemine dikkat çekilmiştir.

Tablo 3. Çalışma sahasında taban suyunda gözlenen toplam çözünmüş tuzların (TDS, g $L^{-1}$ ) zamansal değişimi ve alansal dağılımları (\%)

Table 3. Temporal changes of areal means of total dissolved solids (TDS in the units of $g L^{-1}$ ) in $G W$ and areal coverages (\%)

\begin{tabular}{|c|c|c|c|c|c|c|}
\hline \multirow{3}{*}{ Zaman } & \multirow{3}{*}{$\begin{array}{c}\text { Alansal ortalamalar ve } \\
\text { standart sapmaları }\end{array}$} & \multicolumn{5}{|c|}{ Toplam çözünmüş tuzlar (TDS, $\mathrm{g} \mathrm{l}^{-1}$ ) } \\
\hline & & $<1.4$ & $1.4-2$ & $2-5$ & 5-10 & $>10$ \\
\hline & & \multicolumn{5}{|c|}{ Kapladığı alan (\%) } \\
\hline Şubat/08 & $2.22 \pm 2.700$ & 43.3 & 28.3 & 21.7 & 4.4 & 2.4 \\
\hline Nisan/08 & $2.356 \pm 2.318$ & 39.8 & 20.6 & 31.9 & 5.8 & 1.9 \\
\hline Temmuz/08 & $2.202 \pm 2.250$ & 43.5 & 22.2 & 27.1 & 5.4 & 1.8 \\
\hline Ekim/08 & $2.723 \pm 2.311$ & 35.9 & 16.0 & 35.5 & 10.7 & 1.8 \\
\hline
\end{tabular}

\subsection{Taban suyu sodikliğinin zamansal değişimi}

Taban suyunun alkaliliği (sodikliği), genellikle sodyum adsorpsiyon oranı olan SAR kullanılarak değerlendirilmektedir (Said ve ark., 2021). Araştırmada, gözlem süresi boyunca taban suyunda gözlenen SAR'ın alansal ortalamalarının, eşik SAR değeri olan 13'ün altında (Said ve ark., 2021) ölçülmüştür (Şekil 6). Bununla birlikte, Şekil 6'da görüldüğü gibi, sulama mevsiminin sonunda (ekim ayında), toplam alanın \%10'undan daha geniş alanlarda kritik SAR değerinden daha büyük değerlere ulaşıldığı görülmektedir. Mekansal dağılımlar incelendiğinde, sulama mevsimi başlangıcı olan nisan ayı ve sulamaların en yoğun olduğu temmuz ayı arasındaki dönemde bir fark bulunamamıştır (Şekil 6).

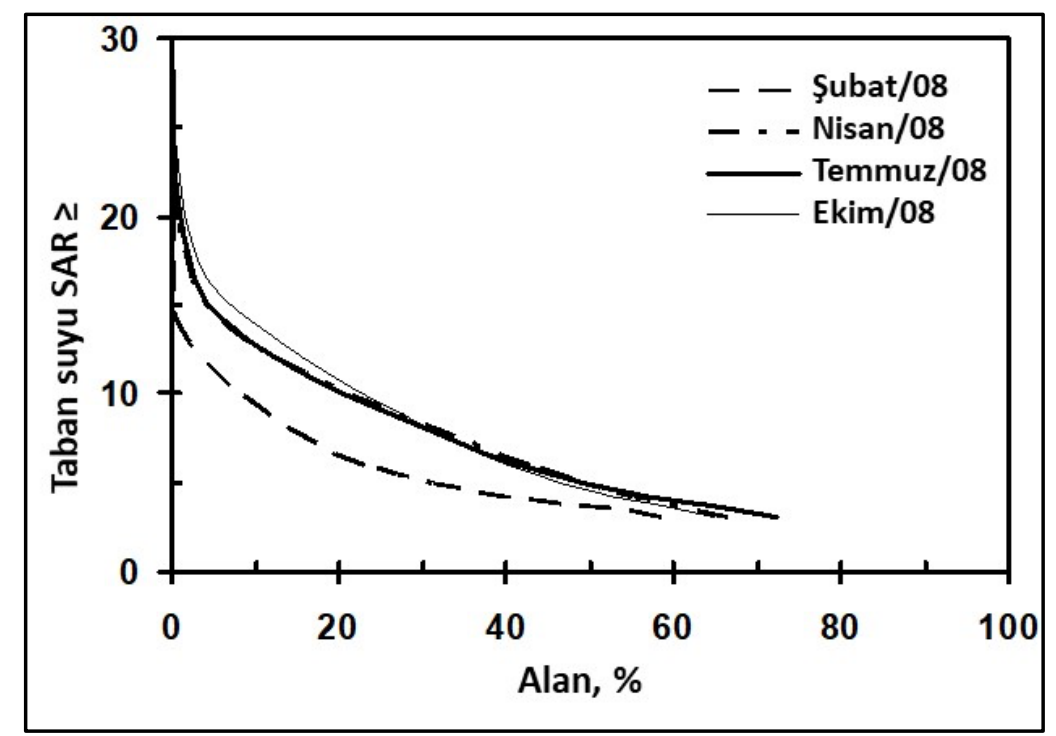

Figure 6. Temporal changes in the hypsometric curves of groundwater SAR in the research area.

\section{Şekil 6. Araştırma sahasında taban suyu SAR değerlerinin hipsometrik ĕgrileri: Mekansal ve alansal değgişimler.}

Taban suyunda tuz içeriğinin yüksek olması, yetersiz drenaj, yüksek SAR değerlerinin tuzluluk ve alkalilik sorunlarını tetikleyeceği (FAO, 2001; Cetin ve Kirda, 2003; Demir ve Antepli, 2004) açıktır. Bu bağlamda taban suyu SAR değerlerine dikkat edilmesi ve sürekli izlenmesi önem arz etmektedir. Aragues ve ark. (2011), sulanan alanlardaki tuzluluğun ve alkaliliğin yetersiz sulama yönetiminin, sulama suyunun düşük randımanlı yüzey sulama yöntemleri ile uygulanmasının bir sonucu olabileceğine işaret etmişler; Akdeniz havzasındaki sulama alanlarında ortaya çıkan sorunlara değinmişlerdir. 


\section{Sonuç}

Araştırma alanında, 60 yıldan daha uzun bir süredir sulu tarım uygulamaları yapılmaktadır. Sulama uygulamalarının yoğun bir şekilde yapıldığı bölgelerde zamanla taban suyu ve tuzluluk gibi sorunlar ortaya çıkabilmektedir.

Kışın meydana gelen yă̆ışlar, araştırma alanının üçte birinden fazlasında ciddi drenaj sorunlarına neden olmuştur. Araştırma alanının kuzey kesimlerinde, taban suyu derinliği kritik seviyelerde $(<1 \mathrm{~m})$ tespit edilmiştir. Sulama uygulamalarının en yoğun temmuz ayında, alanın \%66.3'ünde taban suyu derinliği 1.5 m'den daha sığ bulunmuştur. Araştırma alanındaki drenaj sorununun temel kaynağı kış aylarında yağışlar; yaz aylarında ise aşırı sulama suyu uygulamalarıdır. Yağış̧ı dönemler ile pik sulama mevsiminde araştırma alanının önemli bir kısmında taban suyu derinliği bitki kök bölgesinde kalarak drenaj sorununa neden olmuştur.

Taban suyu tuzluluğunun alansal ortalamaları, kritik değer olan $5 \mathrm{dS} \mathrm{m}^{-1}$ ile karşılaştırıldığında, oldukça düşük bulunmuş̧ur. Bununla birlikte, ortalama taban suyu tuzluluğu, kışın yağışların seyreltme etkisi nedeniyle en düşük değere ulaşmıştır. Ancak, taban suyu EC değerlerinin değişkenliği oldukça yüksek düzeylere çıkmıştır. Alanın \%10'undan fazlasında, kış ayı hariç, yıl boyunca her zaman taban suyu tuzluluğu $>5 \mathrm{dS} \mathrm{m}^{-1}$ değerine sahip olmuştur.

Taban suyunda toplam çözünmüş tuzların şiddeti ve kapladığı alanlar sulama mevsiminin sonunda en yüksek seviye ulaşmıştır. Taban suyunun alansal ortalama SAR değerleri, gözlem süresi boyunca eşik SAR değeri olan 13'ün altında kalmıştır. Bununla birlikte, sulama mevsiminin sonunda kritik değerden daha büyük SAR değerlerine sahip olan ve izlenmesi gereken alanlar, toplam alanın \%10'undan daha büyük bulunmuştur.

Araştırma alanındaki sulama şebekesi, "devamlı akış yöntemi”yle işletilmektedir. Bu işletme yönteminde genellikle gece sulamaları yapılmadığından sulama randımanlarının düşmesine; sistemdeki sulama suyunun geceleri drenaj olarak şebekeden akmasına neden olmuştur. Sulama suyundan tasarruf sağlanması ve aşırı sulama suyu uygulamalarının neden olduğu drenaj sorunlarının azaltılması için sulama yönetiminin gece sulama uygulamalarını teşvik etmesi; yüzey sulama yöntemleri yerine yağmurlama ve damla sulama yöntemlerinin yaygınlaştırılmasına yönelik tedbirlerin ivedilikle alınması önerilmektedir.

\section{Teșekkür}

$\mathrm{Bu}$ araştırma, Avrupa Birliği 6. Çerçeve Programı kapsamında QUALIWATER: Diagnosis and Control of Salinity and Nitrate Pollution in Mediterranean Irrigated Agriculture isimli proje (Proje No: INCO-CT-2005- 015031) ve Çukurova Üniversitesi Katılımlı Araştırma Projesi (Proje No: ZF2006KAP1) ile finanse edilmiştir. Hakkın rahmetine kavuşan Sayın Prof. Dr. Cevat KIRDA Hocamıza, QUALIWATER projesindeki katkıları ve emekleri için sonsuz şükranlarımızı sunarı. 


\section{Kaynakça}

Amezketa, E. (2006). An integrated methodology for assessing soil salinization, a pre-condition for land desertification. Journal of Arid Environments 67: 594-606.

Aragues, R., Urdanoz, V., Çetin, M., Kirda, C., Daghari, H., Ltifi, W., Lahlou, M., Douaik, A. (2011). Soil salinity related to physical soil characteristics and irrigation management in four Mediterranean irrigation districts. Agric. Water Manage. 98: 959-966.

Büyükcangaz, H., Değirmenci, H. (2002). Drenaj sularının sulamada yeniden kullanılması. Su Havzalarında Toprak ve Su Kaynaklarının Korunması, Geliştirilmesi ve Yönetimi Sempozyumu, 18-20 Eylül 2002, Antakya, s. 614-617.

Cemek, B., Guler, M., Arslan, H. (2006). Determination of salinity distribution using GIS in Bafra plain right land irrigated area. Atatürk Üniv. Ziraat Fak. Derg. 37: 63-72.

Cetin, M. (2020). Agricultural Water Use. In: N. B. Harmancioglu, D. Altinbilek (eds.), Water Resources of Turkey, Chapter 9, World Water Resources, Springer Nature Switzerland AG 2020, Vol. 2: 257-302.

Cetin, M., Diker, K. (2003). Assessing drainage problem areas by GIS: A case study in the Eastern Mediterranean Region of Turkey. Irrigation and Drainage 52: 343-353.

Cetin, M., Kirda, C. (2003). Spatial and temporal changes of soil salinity in a cotton field irrigated with low-quality water. Journal of Hydrology 272: $238-249$.

Çetin, M., Kırda, C., Efe, H., Topçu, S. (2007). Aşağı Seyhan Ovası'nda taban suyu derinliği sulama ilişkilerinin coğrafi bilgi sistemi ile irdelenmesi (in Turkish). V. Ulusal Hidroloji Kongresi Bildiriler Kitabı, Orta Doğu Teknik Üniversitesi, 5-7 Eylül 2007, Ankara, Sayfa, pp. 419-428.

Çetin, M., Özcan, H. (1999). Aşağı Seyhan Ovasında Sulanan ve Sulanmayan Alanlarda Meydana Gelen Sorunlar ve Çözüm Önerileri: Örnek Bir Çalışma. TÜBİTAK Turkish Journal of Agriculture and Forestry 23(1): 207-217.

Çölaşan, U. E. (1970). Türkiye İklim Klavuzu. Ongun Kardeşler Matbaası, (Turkish) Ankara.

Demir, N., Antepli, N. (2004). Aşağı Seyhan Ovası sulaması taban suyu ve tuzluluk problemleri değerlendirme çalışması. Sulana Alanlarda Tuzluluk Yönetimi Sempozyumu, 20-21 Mayıs 2004, DSİ Genel Müdürlüğü, Ankara.

Dinç, U., Sarı, M., Şenol, S., Kapur, S., Sayın, M., Derici, M., Çavuşgil, V., Gök, M., Aydın, M., Ekinci, H., Ağca, N., Schlichting, E. (1995). Çukurova Bölgesi Toprakları. Çukurova Üniversitesi Ziraat Fakültesi yardımcı ders kitabı, No:26, (Turkish) Adana.

DSİ (1982). ASO IV. Merhale Projesi Planlama Drenaj Raporu, Ankara.

FAO (2001). Drainage and sustainability. IPTRID Issues Paper No. 3, Food and Agriculture Organization of the United Nations, Rome, Italy.

FAO (2002). Crops and drops: Making the best use of water for agriculture, food and agriculture organization of the United Nations. Rome, Italy.

Gündoğdu, K. S. (2004). Sulama proje alanlarındaki taban suyu derinliğinin jeoistatistiksel yöntemlerle değerlendirilmesi. Uludağ $\ddot{U}$. Ziraat Fak. Der. 18(2): 85-95.

İstanbulluoğlu, A., Konukcu, F., Kocaman, İ. (2006). Development of water resources and agricultural practices under irrigation in Thrace Region: Analysis of existing data for the solution of problems. Tekirdă̆ Ziraat Fakültesi Dergisi- Journal of Tekirdag Agricultural Faculty 3(2): 139-152.

Kaman, H., Çetin, M., Kirda, C. (2011). Effects of Lower Seyhan Plain irrigation on groundwater depth and salinity. Journal of Food, Agriculture \& Environment 9(1): 648-652.

Konak, C., Y1lmaz, R., Arabacı, O. (1999). Salt tolerance in Aegean Region's wheats. (Turkish with English Abstract) Tr. J. of Agr. and For. 23(5): 1223-1229.

Konukcu, F., Akbuğa, R. (2006). Impact of shallow and saline water tables on the Soil's Water and Salt Balance of Konya-Cumra District under Irrigation. Tekirdă̆ Ziraat Fakültesi Dergisi- Journal of Tekirdag Agricultural Faculty 3(2): 105-117.

Lamsal, K., Paudyal, G. N., Saeed, M. (1999). Model for assessing impact of salinity on soil water availability and crop yield. Agr. Water Manage. 41: 57-70.

Said, A. A., Yurtal, R., Cetin, M., Golpinar, M. S. (2021). Evaluation of some groundwater quality parameters using geostatistics in the urban coastal aquifer of Bosaso plain, Somalia. Journal of Agricultural Sciences 27(1): 88-97.

Szabolcs, I. (1989). Salt-affected soils. CRC Press, Inc. Boca Raton, Fla., p. 274.

Thales, (2005). Magellan explorist 600 reference manual. Thales S. A., USA, pp. 123. 